\title{
Two New Species of the Genus Dichomeris Hübner from Thailand (Lepidoptera, Gelechiidae)
}

\author{
Kyu Tek Park' and Margarita G. Ponomarenko² \\ 'Center for Insect Systematics, Kangwon National University, Chuncheon, 200-701, Korea \\ "Institute of Biology and Pedology, Far East Branch of Russian Academy of Sciences, \\ Vladivostok, 690022, Russia
}

(Received 16 January 1997; Accepted 5 December 1997)

\begin{abstract}
Two new species of the genus Dichomeris Hübner, 1818, D. parallelosa sp. nov. and $D$. quadrata sp. nov., are described from Thailand, with illustrations of their genitalia.

Key Words: Dichomeris parallelosa sp. nov., Dichomeris quadrata sp. nov., Gelechiidae, Lepidoptera, Thailand.
\end{abstract}

\section{Introduction}

The lepidopteran genus Dichomeris Hübner, 1818 is widely distributed throughout the world, with several hundred species. Recently Park (1994) reported 18 species from Korea, Park and Ilodges (1995) reviewed 43 species from Japan and Taiwan, and $\mathrm{Li}$ and Zheng (1996) reported 72 species from the continental China. However, it is a poorly known group in Thailand, as well as the other members of the Gelechiidae. The material dealt with in this paper is based on the recent collection of the genus in the Natural History Museum, London, made by Dr. I. J. Kitching and Mr. A. Cotton in Thailand from 1988 to 1994.

Dichomeris parallelosa Park and Ponomarenko, sp. nov.

(Figs 1, 3-6)

Diagnosis. The new species is superficially similar to the members of the acuminata species-group (see Park and Hodges 1995), but it is separable from the previously known species of that group by the lateral lobes of the juxta, which are strongly ankylosed with the dorsal surface of the aedeagus.

Description. Male. Wingspan 11.0-11.5 mm. Head orange gray on frons, light brown on vertex, with erect scales laterally. Antenna about $4 / 5$ of forewing in length; flagellum dark brown on upper surface, densely ciliate with short sensory cilia ventrally. Ocellus absent. Second segment of labial palpus relatively slender, directed forward, with rough, erect scales beyond middle dorsally, brown on outer surface and slightly paler, yellowish white on upper $1 / 4$ of inner surface, with whitish apical tip; third segment slender, slightly shorter than second. Thorax and tegula concolorous. Ventral surface of legs dark brown. Mesothoracic anepisternum lacking a pair of long scale tufts. Forewing elongate, more or less narrow; apex relatively acute; ground colour light brown on upper $1 / 3$ and dark brown on lower $2 / 3$ of wing, without 
distinct markings; costa almost straight; R4 and R5 stalked beyond middlc. Hind wing gray; M1 approximated to Rs near base; Rs to apex; M3 close to CuA1 at base; CuA2 arising from near lower corner of cell; apex sharply pointed; cell closed; cubital pecten not developed.

Male genitalia (Figs 3-6). Uncus rather broad, short, with rounded distal margin. Gnathos hook-like; culcitula emarginated at middle on distal margin. Valva relatively short, not reaching apex of uncus, gently dilated towards apex. Ventral free lobes ("valvella" by Ponomarenko 1992) slender, relatively long, slightly shorter than $1 / 3$ length of valva, bearing long setae apically, curved inwardly. Appendix appendicular weakly developed. Vinculum relatively broad; lateral lobes digitate, long, with short spines sparsely near apex; juxta ("sicae" by Park 1994) almost symmetrical, slender, left lobe slightly shorter than right one, running closely parallel, separated from base, pointed at apex; two heavily sclerotized outer lobes arising from base of juxta laterally, strongly ankylosed with dorsal surface of aedeagus, left one slightly shorter than right one. Aedeagus with heavily sclerotized, sharply extended ventral lobe, two lateral lobes curved ventrally (left one shorter, sickle-shaped, curved at right angle; right one longer, gently arched), and weakly sclerotized, broad, inner plate.

Type. Holotype: male, NW Thailand, Chiang Mai, Doi Suthep-Pui NP, 24. II. 1989 (I. J. Kitching and A. M. Cotton). Paratype: $10^{7}$, NW Thailand, Chiang Mai, $24 \mathrm{~km}$ Mae Rim/Samoeng Rd, 1,100 m, 5. II. 1989 (I. J. Kitching and A. M. Cotton). Types are deposited in the Natural History Museum, London.

Distribution. Thailand.

Dichomeris quadrata Park and Ponomarenko, sp. nov.

(Figs 2, 7-11)

Diagnosis. In the colour pattern of forewings, this new species is very similar to Dichomeris davisi Park and Hodges, 1995, and the male genitalia also resemble those of the latter. But it can be separated from the latter by the larger size of the forewing, the almost symmetrical juxta, and the extremely stout aedeagus. It is also very similar to D. horoglypta Meyrick, 1932 in the male genitalia, but it can be easily separated from the latter by the short valvae, large appendix appendicular, and stout aedeagus. This species also belongs to the acuminata species-group (Park 1995).

Description. Male and female. Wingspan 14.5-15.5 mm. Head shiny orange white on frons, covered with light brown appressed scales on vertex. Antenna with slender, brown pedicel; flagellum lacking sensory cilia on ventral surface. Ocellus present. Second segment of labial palpus almost rectangular, extremely large, brown on outer surface, yellowish white centrally on inner surface; third segment very slender, almost equal to second, strongly upturned. Tegula and thorax grayish brown. Ventral surface of thorax yellowish white laterally. Ventral surface of legs grayish brown. Male lacking a pair of long scaletufts arising from mesothoracic anepisternum. Forewing elongate, light brown, with irregular scattering of dark brown scales; costa slightly incurved at middle; postmedian line at $4 / 5$ of forewing, edged with yellowish orange scales outwardly, outer area dark brown; three short lines of brown scales inwardly, more distinct on costal half of wing; cilia golden yellow with dark brown tips along termen, dark brown near tornus. R3 running very closely along R4 +5 to middle length; R4 and R5 stalked for 2/3 length; R5 to apex. 

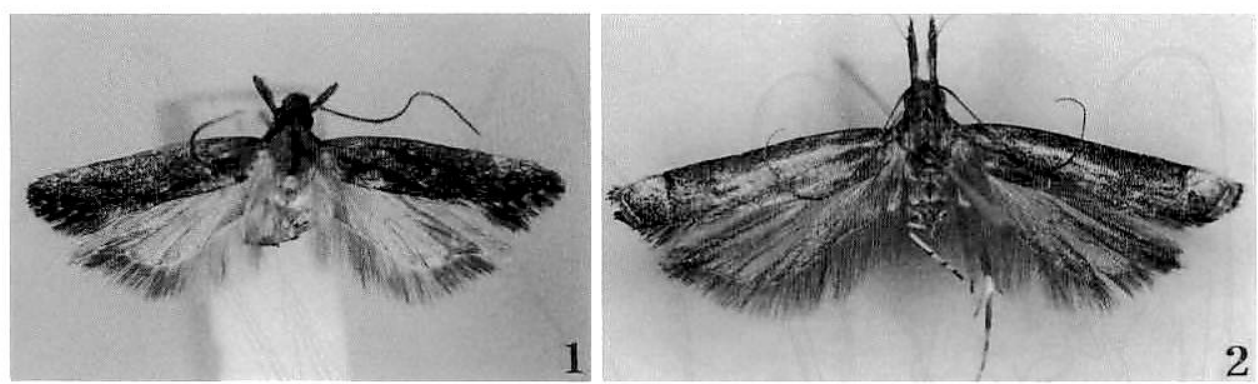

Figs 1-2. Adults. 1, Dichomeris parallelosa sp. nov., $\sigma^{\top}$, holotype; 2, Dichomeris quadrata sp. nov., $\sigma^{7}$, holotype.
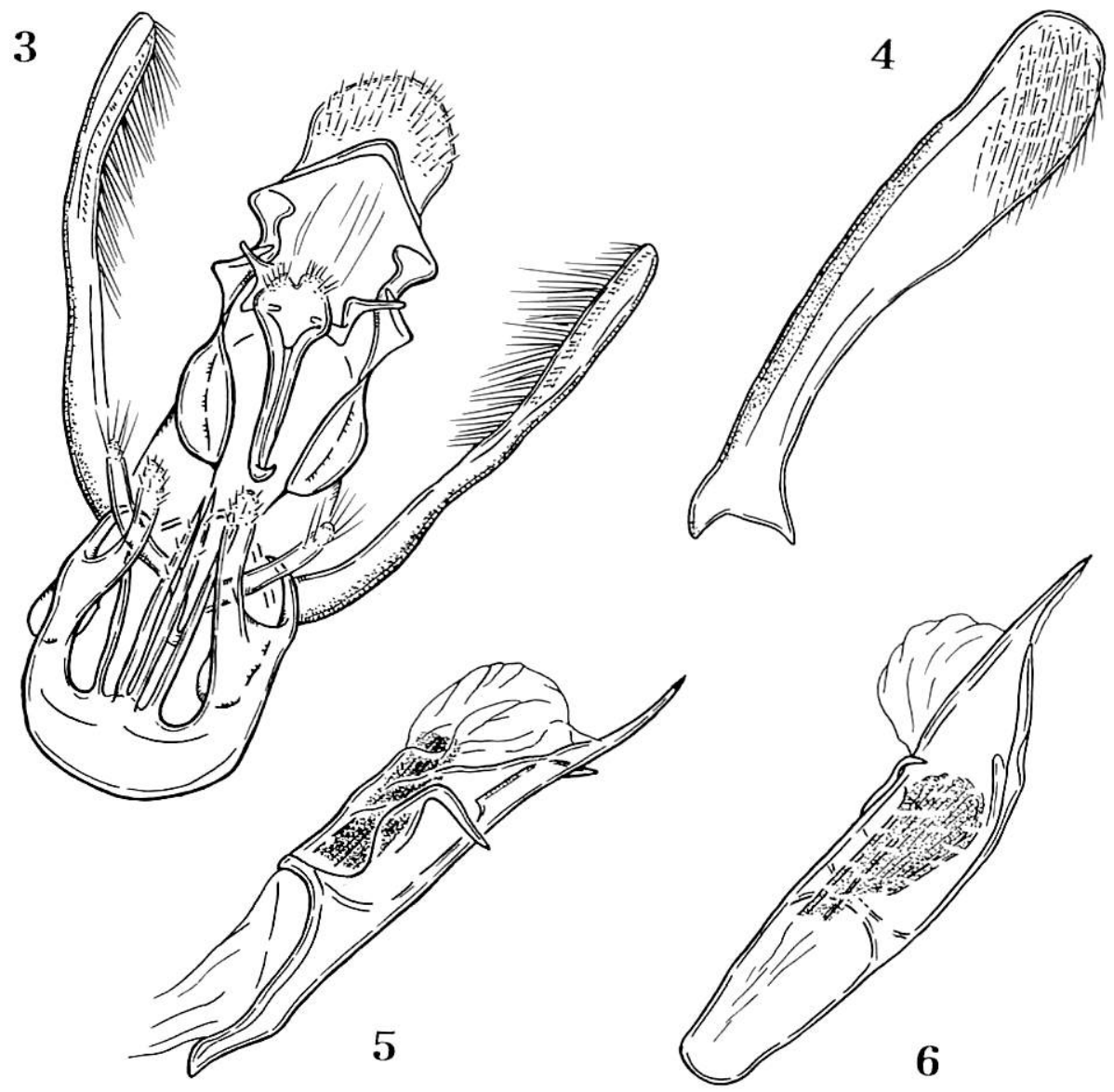

Figs 3-6. Male genitalia of Dichomeris parallelosa sp. nov.; 3, ventral aspect of genitalia; 4, left valva; 5 , lateral aspect of aedeagus; 6 , ventral aspect of aedeagus. 


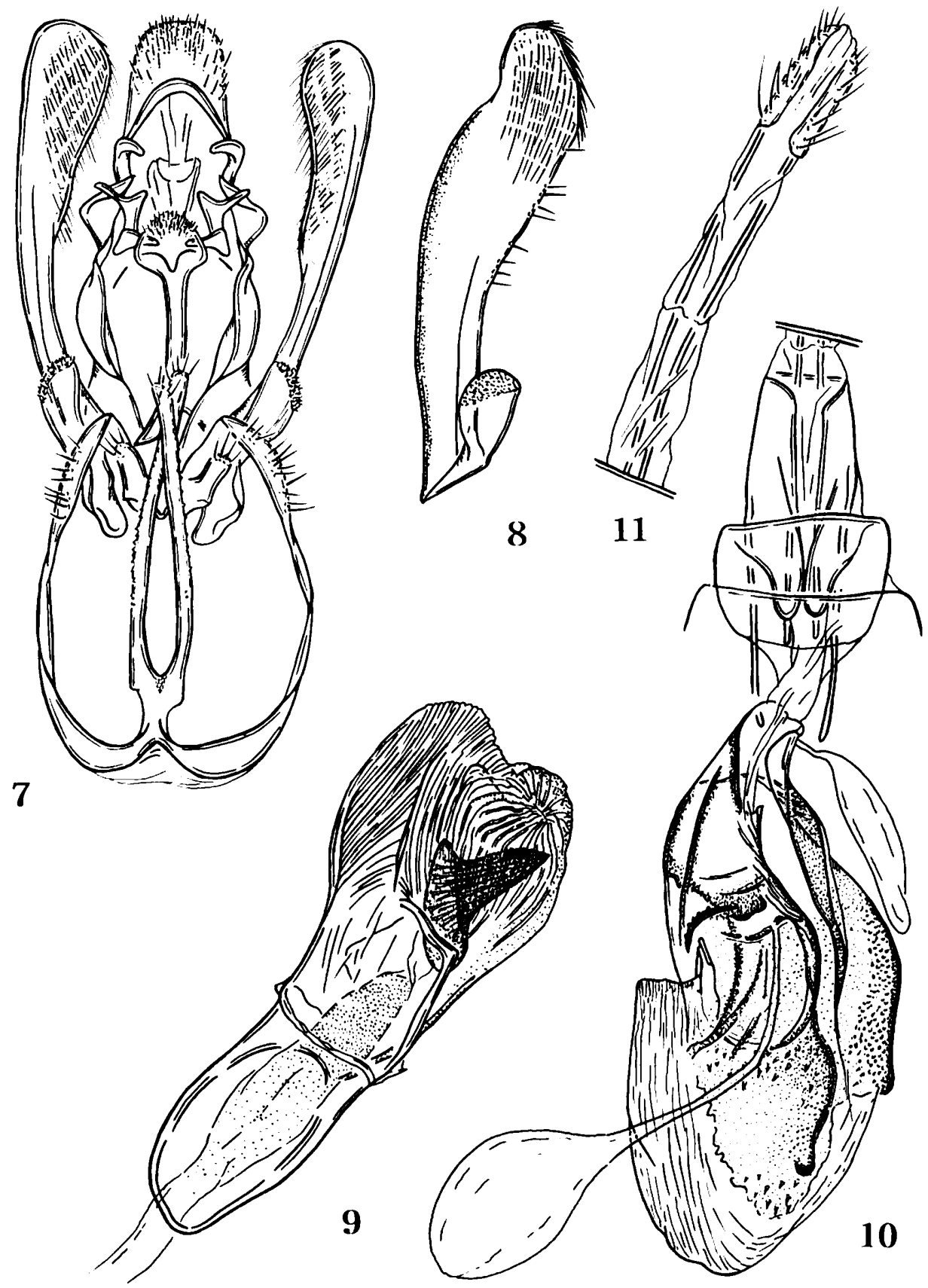

Figs 7-11. Genitalia of Dichomeris quadrata sp. nov.; 7, ventral aspect of male genitalia; 8 , left valva; 9 , ventral aspect of aedeagus; 10 , ventral aspect of female genitalia, 11, papillae anales. 
0. Hindwing gray; termen oblique, heavily sinuated; apex relatively pointed; cubital pecten well developed; cell closed.

Male genitalia (Figs 7-9). Uncus relatively long, with rounded distal margin. Gnathos relatively stout, slightly narrowed at base; culcitula relatively small, rounded on distal margin. Tegumen dilated towards base. Valva not exceeding apex of uncus, dilated towards apex, slightly emarginated on dorsal margin before apex, its distal part curved inwardly; ventral free lobes short, broad, with short setae apically. Appendix appendicular large, spatulate, about $1 / 4$ length of valva. Vinculum narrow, band-like, with numerous small setae on basal 1/3 laterally, lacking lateral lobes; saccal region with strong break. Lobes of juxta almost symmetrical, narrowed at base, joined shortly to base of juxta; serrated beyond basal $1 / 4$ laterally. Aedeagus extremely stout, lacking lateral lobes; basal zone about $2 / 3$ in length; cornutus large, long cone-shaped, with broad base.

Female genitalia (Figs 10-11). Ovipositor extremely long, with membrane between eighth and ninth segments about three times as long as papillae anales. Apophyses anteriores about 1/3 length of apophyses posteriores. Eighth sternite roundly emarginated on distal margin medially, extending to rounded lobes laterally. Ductus bursae membranous, very short, less than $1 / 5$ length of corpus bursae; ductus seminalis membranous, arising from near basal end of corpus bursae laterally. Corpus bursae extremely large, with heavily sclerotized complex at middle and on right side, bearing numerous spicules on inner surface of right side; signum lacking; accessary bursae membranous arising from middle of ventral surface.

Types. Holoty pe: male, N Thailand, Mae Hong Son, Pai District, Doi Mae Ya, 1,240 m, 18. VII. 1990 (I. J. Kitching and A. M. Cotton). Paratype: 1 ㅇ, NW Thailand, Chiang Mai, 15 km Samoeng/Hang Dong Rd, 5-12. VI. 1988 (I. J. Kitching and A. M. Cotton). Types are deposited in the Natural History Museum, London.

Distribution. Thailand.

\section{Acknowledgements}

We wish to express our thanks to Dr. I. J. Kitching and Mr. A. Cotton, the Natural History Museum, London, who collected these specimens from Thailand, and to $\mathrm{Mr}$. M. Shaffer of the same museum, who allowed the first author to study them.

\section{References}

Li, H. and Zheng, Z. 1996. A systematic study on the genus Dichomeris Hübner, 1818 from China (Lepidoptera, Gelechiidae). SHILAP Revista de Lepidoptera 24: 229-273.

Park, K. T. 1994. Genus Dichomeris in Korea, with description of seven new species (Lepidoptera, Gelechiidae). Insecta Koreana 11: 1-25.

Park, K. T. and Hodges, R. W. 1995. Gelechiidae (Lepidoptera) of Taiwan III. Systematic revision of the genus Dichomeris in Taiwan and Japan. Insecta Koreana 12:1-101.

Ponomarenko, M. G. 1992. Functional morphological analysis of male genitalia of the gelechiid moths of the subfamily Dichomeridinae sensu novo (Lepidoptera, Gelechiidae). Entomological Review 71(1): 160-177 [In Russian]. 
